\title{
Plasmodium falciparum histidine-rich protein 2 diversity in Ghana
}

\author{
Otchere Addai-Mensah" ${ }^{*}$, Bismarck Dinko², Mark Noagbe', Selassie Louis Ameke ${ }^{3}$, Max Efui Annani-Akollor ${ }^{4}$, \\ Eddie-Williams Owiredu', Kofi Mensah', Richmond Tackie², Eliezer Togbe ${ }^{1}$, Comfort Agyare-Kwabi², \\ Charles Gyasi ${ }^{1}$, Constance Adu-Gyamfi ${ }^{1}$ and Alexander Yaw Debrah ${ }^{1}$
}

\begin{abstract}
Background: In the absence of microscopy, Plasmodium falciparum histidine-rich proteins 2 (PfHRP2)-based rapid diagnostic tests (RDTs) are recommended for the diagnosis of falciparum malaria, particularly in endemic regions. However, genetic variability of the pfhrp2 gene threatens the usefulness of the test due to its impact on RDT sensitivity. This study aimed to investigate the diversity of pfhrp2 in malaria cases among children in Ghana.
\end{abstract}

Methods: A cross-sectional study was conducted at the Adidome Government Hospital in the Volta Region of Ghana. A total of 50 children with mean age of $6.6 \pm 3.5$ years and diagnosed falciparum malaria were included. Blood samples were collected for complete blood count, malaria parasite identification and counting using auto analyzer and microscopy, respectively. DNA was isolated from blood-spotted Whatman filters, amplified and sequenced. Nucleotide sequences were translated in silico to corresponding amino acids and the deduced amino acids sequences were analyzed for diversity using Mega X.

Results: The number of repeats and number of each repeat within PfHRP2 varied between isolates. Twelve rare PfHRP2 repeat types, two of which are previously unreported, were identified in this study. The HRP2 sequence obtained in this study shared high similarities with isolates from Kenya. Using Baker's regression model, Group B was the highest occurring type (58.0\%). Screening of all sequences for epitopes recognized by PfHRP2-specific monoclonal antibodies (mAbs), the predominant motif was AHHAADAHH, which is recognized by the C1-13 mAbs.

Conclusion: This study reports diversity of $P$. falciparum HRP2 in samples from Ghanaian children with symptomatic malaria. The findings of this study highlight the existence of extra amino acid repeat types which adds to the PfHRP2 antigenic variability.

Keywords: Malaria, Plasmodium falciparum, Histidine-rich protein 2, Rapid diagnostic test, Ghana

\section{Background}

Malaria, which causes substantial morbidity and mortality, is a major public health problem in sub-Saharan Africa, Asia and Latin America [1]. It claims the life of a child under 5 years old every two minutes in sub-Saharan

\footnotetext{
*Correspondence: drmedmozart@yahoo.com

${ }^{1}$ Department of Medical Diagnostics, Faculty of Allied Health Sciences,

Kwame Nkrumah University of Science and Technology, Kumasi 00233, Ghana

Full list of author information is available at the end of the article
}

Africa and has annual infection and mortality rates of 191 million and 395,000 individuals, respectively [2, 3]. In Ghana, malaria remains a major cause of loss of days of healthy life, accounting for about $20 \%$ of child deaths, $40 \%$ of child hospital admissions and more than $50 \%$ of outpatient attendances [4-7].

Although microscopic examination of stained blood smears remains the gold standard for malaria diagnosis, its benefit is limited by the absence of adequate skilled personnel and infrastructural and logistic resources, particularly in resource-poor areas [8]. To overcome

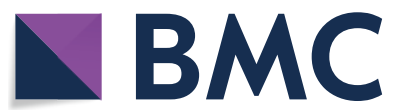

(c) The Author(s) 2020. This article is licensed under a Creative Commons Attribution 4.0 International License, which permits use, sharing, adaptation, distribution and reproduction in any medium or format, as long as you give appropriate credit to the original author(s) and the source, provide a link to the Creative Commons licence, and indicate if changes were made. The images or other third party material in this article are included in the article's Creative Commons licence, unless indicated otherwise in a credit line to the material. If material is not included in the article's Creative Commons licence and your intended use is not permitted by statutory regulation or exceeds the permitted use, you will need to obtain permission directly from the copyright holder. To view a copy of this licence, visit http://creativeco mmons.org/licenses/by/4.0/. The Creative Commons Public Domain Dedication waiver (http://creativecommons.org/publicdomain/ zero/1.0/) applies to the data made available in this article, unless otherwise stated in a credit line to the data. 
this problem, the World Health Organization (WHO) included rapid diagnostic tests (RDTs), a less expensive and easily accessible test, as one of the alternative testing systems for malaria diagnosis prior to the prescription of anti-malarial drugs.

Since its development in the 1990s, and with more than 200 currently available brands, there have been consistent reports of observable increase in malaria RDT sales worldwide $[9,10]$. Most malaria RDTs exploit the presence of Plasmodium falciparum histidine-rich protein 2 (PfHRP2) for the detection of P. falciparum [11]. The presence of repetitive epitopes that enable their detection by multiple antibodies and their abundance in blood during the blood-stage of malaria infections has made PfHRP2 a common antigenic target for RDTs [12, 13].

In 2010, Ghana implemented the test-before-treat guideline for malaria where RDT use was promoted to facilitate diagnosis [14]. However, beside low parasite levels especially in asymptomatic cases, improper interpretation of RDT results and/or the handling and storage of RDT kits, deletion of the pfhrp 2 gene and extensive antigen diversity have contributed to discrepancies in RDT sensitivity [15-20], threatening the future use of the test method, particularly in malaria-endemic regions, such as Ghana. Indeed, a recent study in Ghana reported pfhrp 2 gene deletion in 33 and 36\% of microscopicallyconfirmed and PCR-confirmed RDT positive samples, respectively [21]. Over the past decade, several countries, especially in Africa, have reported cases of P. falciparum isolates with deleted pfhrp2, and isolates with high pfhrp2 diversity [17, 18, 22-26], with potential negative implications for malaria control and elimination programmes. These notwithstanding, studies on $p f h r p 2$ gene deletion and diversity of the pfhrp 2 gene in Ghana, a malaria-endemic country, are lacking.

This study aimed to investigate the diversity of PfHRP2 in malaria cases among children in Ghana.

\section{Methods}

\section{Study design/setting and participants}

A cross-sectional study was conducted between January and June 2019 at the Adidome Government Hospital in the Volta Region of Ghana. The Volta Region has perennial malaria transmission, with the predominant parasite being $P$. falciparum. The regional prevalence of falciparum malaria is $45.27 \%$ among children [27]. In the study, 50 children between the ages of 3 and 11 years diagnosed with falciparum malaria were included. Samples were obtained prior to initiation of anti-malarial therapy.

\section{Sample collection and laboratory analysis}

Three ml of blood was aseptically obtained from each participant and dispensed into K3 EDTA tubes. Complete blood count was performed on the anticoagulated whole blood using Sysmex KX-21 N auto analyzer (Sysmex Corporation, Japan). To reassess falciparum malaria, thick and thin blood films were prepared and stained with $10 \%$ Giemsa for microscopic identification and counting of parasites. The parasite density was calculated by assuming a standard white blood cell (WBC) count of $8000 / \mu \mathrm{l}$ or 4.5 million red blood cells (RBCs)/ $\mu \mathrm{l}$ in accordance with WHO standards [28].

Additionally, 5 drops of the blood (each drop corresponding to about $30 \mu \mathrm{l}$ of blood) were spotted onto Whatman $^{\mathrm{TM}}$ filter papers (Schleicher and Schuell BioScience Inc, Keene, New Hampshire, USA), air dried and individually kept in zip-lock plastic bag for subsequent PCR analysis.

\section{Parasite DNA extraction and molecular analysis}

DNA isolation from Whatman filter papers was based on the Chelex-based technique as previously described [29]. PCR amplification of the exon 2 of the pfhrp 2 gene was performed using the semi-nested amplification approach, as previously described by Baker et al. [16]. PCR reactions were carried out in $25 \mu \mathrm{l}$ volume for the primary and $35 \mu \mathrm{l}$ volume for the semi-nested reactions. The forward and reverse primers targeting the exon 2 of the pfhrp2 gene are shown in Additional file 1: Table S1. For both primary and secondary PCR reactions, DNA was denatured at $96^{\circ} \mathrm{C}$ for $10 \mathrm{~min}$ followed by 40 cycles of denaturation at $95^{\circ} \mathrm{C}$ for $50 \mathrm{~s}$, annealing at $55^{\circ} \mathrm{C}$ for $50 \mathrm{~s}$, extension at $68^{\circ} \mathrm{C}$ for $1 \mathrm{~min}$ and a final extension at $72{ }^{\circ} \mathrm{C}$ for $5 \mathrm{~min}$. Genomic DNA from 3D7 (wild type) P. falciparum and nuclease-free water were used as positive and negative controls, respectively. After secondary amplification, amplicons were separated by electrophoresis on $2 \%$ agarose gels, stained with ethidium bromide and visualized under UV light. Sequencing of the pfhrp 2 gene was performed by Inqaba Biotechnical Industries (Pty) Ltd, South Africa (https://www.inqababiotec.co.za/). Nucleic acid sequences were deposited at the National Center for Biotechnology Information (NCBI) (Genbank accession numbers: MT094447-79).

\section{Data analysis}

Mega X version 10.1.6 [30] was used for sequence analysis. Nucleotide sequences were translated in silico to corresponding amino acids using the correct open reading frame. Amino acid repeats were numerically coded based on previous reports $[16,18,31]$; the frequencies and percentages of each amino acid repeat were estimated. To compare amino acid sequences in this study with previously published data, protein-protein BLAST (BLASTP) analysis of the sequences obtained in this study was performed to obtain homologous sequences the GenBank 
database at the NCBI. The PfHRP2 amino acid sequences from this study and the homologous sequences downloaded from the NCBI were aligned using the ClustalW tool and a cladogram was built using the Maximum Likelihood method and Dayhoff matrix-based model, with bootstrap consensus tree inferred from 1000 replicates. Although RDTs results were unavailable, the study also sought to determine the diversity of PfHRP2 with respect to RDT sensitivity. To achieve this, the product of repeats type 2 and 7 was calculated; classification and interpretation was based on Baker's regression model [16]. Screening of the sequences from this study for epitopes recognized by PfHRP2-specific monoclonal antibodies (mAbs) [32] were also performed. Flow chart of sampling, testing and analysis is shown in Fig. 1.

\section{Results}

A total of 50 children with mean age of $6.6 \pm 3.5$ years were included. There were more females than males (56.0 vs 44.0\%). The average RBC count, haemoglobin, haematocrit, mean cell volume, mean cell haemoglobin, mean cell haemoglobin concentration, WBC count, platelet count, and parasite density were $4.0 \pm 0.7 \times 10^{6} / \mu \mathrm{L}$, $10.5 \pm 1.6 \mathrm{~g} / \mathrm{dL}, 30.8 \pm 4.6 \%, 77.2 \pm 6.4 \mathrm{fL}, 26.7 \pm 4.1 \mathrm{pg}$,
$34.5 \pm 3.7 \quad \mathrm{~g} / \mathrm{dL}, \quad 7.5 \pm 2.7 \times 10^{3} / \mu \mathrm{L}, \quad 101.0 \quad(63.0-$ $171.3) \times 10^{3} / \mu \mathrm{L}$, and $35,411.0(15,183.9-65,280.7) / \mu \mathrm{L}$, respectively (Table 1 ).

Thirty-three different PfHRP2 amino acid sequences were identified among 50 PfHRP2 sequences obtained in this study. The size of PfHRP2 ranged from 225 to 304 amino acids among all isolates and 25 to 38 amino acid repeat types per isolate. The total number of repeats and the number of each repeat within PfHRP2 varied between isolates. Repeat types 2, 6, 7 and 8 were observed in $100 \%$ of the isolates. Repeat types 5 and 12 were observed in $98 \%$ whereas types 1, 3 and 10 were found in $92-96 \%$ of the samples. The repeat types 4 and 13 occurred in 26 and $10 \%$ of the isolates, respectively. None of the samples had repeat types 9 and 11 (Table 2).

Twelve rare PfHRP2 repeat types, two of which are previously unreported, were identified in this study; the two were APDAHHVAD and AHHAAAHDEAALI. Of the rare repeat types, types 2 (AHHAHHAAH) and 7 (AHHAAH) had the highest frequency (Table 3).

Predominant repeat types in this study were used to model the structural organization of PfHRP2 in Ghana. Although the structural organization of the PfHRP2 repeat types was variable, the repetitive regions found in

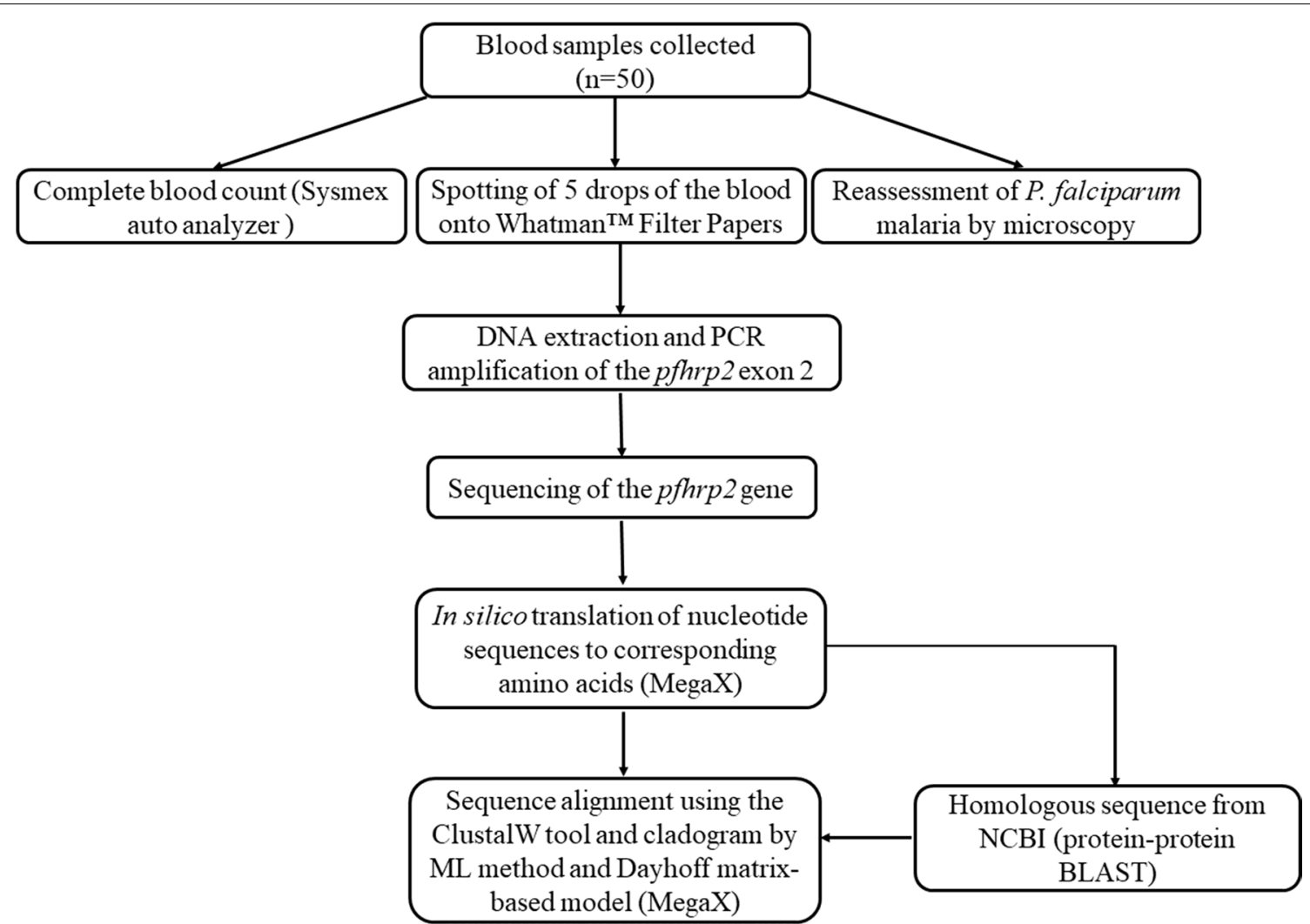

Fig. 1 Flow chart of sampling, testing and analysis 
Table 1 Demographics and haematological profile of the study population

\begin{tabular}{|c|c|c|}
\hline Variables & Mean \pm SD & Min-max \\
\hline Age (years) & $6.6 \pm 3.5$ & $1-14$ \\
\hline Gender $^{\mathrm{a}}$ & $n$ & $\%$ \\
\hline Female & 28 & 56.0 \\
\hline Male & 22 & 44.0 \\
\hline $\mathrm{RBC}\left(\times 10^{6} / \mu \mathrm{L}\right)$ & $4.0 \pm 0.7$ & $2.0-5.3$ \\
\hline $\mathrm{Hb}(\mathrm{g} / \mathrm{dL})$ & $10.5 \pm 1.6$ & $6.3-13.7$ \\
\hline НCT (\%) & $30.8 \pm 4.6$ & $16.1-38.6$ \\
\hline MCV (fL) & $77.2 \pm 6.4$ & $62.1-90.8$ \\
\hline $\mathrm{MCH}(\mathrm{pg})$ & $26.7 \pm 4.1$ & $18.7-45.6$ \\
\hline $\mathrm{MCHC}(\mathrm{g} / \mathrm{dL})$ & $34.5 \pm 3.7$ & $29.9-57.8$ \\
\hline WBC $\left(\times 10^{3} / \mu \mathrm{L}\right)$ & $7.5 \pm 2.7$ & $2.4-12.8$ \\
\hline $\operatorname{PLT}\left(\times 10^{3} / \mu \mathrm{L}\right)^{\mathrm{b}}$ & $101.0(63.0-171.3)$ & $20.0-365.0$ \\
\hline $\begin{array}{l}\text { Parasite density } \\
\quad(\text { parasites } / \mu \mathrm{L})^{\mathrm{b}}\end{array}$ & $35,411.0(15,183.9-65,280.7)$ & $568.0-1,033,730.0$ \\
\hline
\end{tabular}

RBC red blood cell count, $H b$ haemoglobin, $H C T$ haematocrit, $M C V$ mean cell volume, $M C H$ mean cell haemoglobin, $M C H C$ mean cell haemoglobin concentration, WBC white blood cell count, $P L T$ platelet count

a Presented as frequencies and percentages

b Presented as medians (interquartile ranges)

Table 2 Frequencies and proportions of pfhrp2 amino acid repeat types

\begin{tabular}{lllcl}
\hline Code & Repeat sequences & $\begin{array}{l}\text { Repeat } \\
\text { frequency }\end{array}$ & $\begin{array}{l}\text { Repeat } \\
\text { percentage }\end{array}$ & Range \\
\hline Type 1 motif & AHHAHHVAD & 142 & 94.0 & $0-9$ \\
Type 2 motif & AHHAHHAAD & 572 & 100.0 & $6-16$ \\
Type 3 motif & AHHAHHAAY & 67 & 92.0 & $0-3$ \\
Type 4 motif & AHH & 20 & 26.0 & $0-3$ \\
Type 5 motif & AHHAHHASD & 58 & 98.0 & $0-3$ \\
Type 6 motif & AHHATD & 178 & 100.0 & $2-7$ \\
Type 7 motif & AHHAAD & 312 & 100.0 & $3-12$ \\
Type 8 motif & AHHAAY & 65 & 100.0 & $1-3$ \\
Type 10 motif & AHHAAAHHATD & 74 & 96.0 & $0-2$ \\
Type 12 motif & AHHAAAHHEAATH & 50 & 98.0 & $0-1$ \\
Type 13 motif & AHHASD & 5 & 10.0 & $0-1$ \\
\hline
\end{tabular}

most of the samples from this study started with type 1 (94.0\%) and all PfHRP2 sequences terminated with type $12(100.0 \%)$ (Fig. 2a). Fifty-four per cent of the isolates had a semi-conserved PfHRP2 repeat type motif composed of repeat types $2,3,5,7,8,2$, and 7 . Partial amino acid repeat motif comprising types $7,8,2$ and 7 was found in $34.0 \%$ of the isolates.

To explore the similarities between the modelled PfHRP2 sequence obtained from the Ghanaian isolates and those from other regions available at the NCBI, BLASTP analysis of the amino acid sequences were performed. Seven hits (Accession numbers: QBC65525.1, QBC65570.1, QBC65591.1, QBC65640.1, QBC65657.1, QBC65674.1 from isolates in Kenya; AKO62989.1 from China-Myanmar border area) were obtained (Fig. 2b; Additional file 1: Table S2). The modelled HRP2 sequence shared $85-94 \%$ similarity with Kenyan isolates and 94\% similarity with the isolates from China-Myanmar border area. BLASTP of the sequences from each of the 50 samples revealed that $78.0 \%(39 / 50)$ have high similarities with isolates from Kenya, highlighting possible shared identity between PfHRP2 from Ghana and Kenya (Additional file 1: Table S3).

Although data on RDTs were unavailable, an obvious limitation of the study, the Baker model [16] was used to determine the distribution on the basis of PfHRP2 diversity with respect to RDT sensitivity. Isolates were classified as Groups A, B, I and C if their Baker repeat (type $2 \times$ type 7) was $>100,50-100,44-49$ and $<43$, respectively. Group B was the highest occurring type (58.0\%), followed by Group C (22.0\%) (Table 4).

Due to the relatively high percentage of Group $\mathrm{C}$ isolates $(22.0 \%)$, which have been reported to be associated with RDT non-sensitivity [33] obtained in this study, the distribution of possible epitopes to be targeted by $\mathrm{mAb}$ RDTs based on the study by Lee et al. [32] was explored. The predominant motif among the 50 isolates was AHHAADAHH, which is recognized by the C1-13 mAb, followed by AHHAHHA, recognized by mAb 3A4. None of the isolates in this study had the AYAHHAHHAAY motif, while the HAHHAHHAADAHH motif, recognized by C2-3, occurred at a lower frequency (Table 5).

\section{Discussion}

In Africa, $P$. falciparum is the most common malariacausing parasite. Microscopy is the gold standard for the diagnosis of malaria; however, in its absence, RDT has been recommended by WHO for use in malaria diagnosis. The majority of commercially available RDTs target the PfHRP2; however, the future benefit of these RDTs is in jeopardy due to reports of $P$. falciparum isolates that lack the pfhrp 2 gene (deletion) and the presence of isolates with variants of the gene (diversity) [15-19, 22, 23]. It is thus of public health significance to assess the diversity of the pfhrp2, especially in different parts of Africa where the disease exerts a high rate of morbidity and mortality, particularly among children.

This study presents an analysis of the diversity of $p f h r p 2$ among $P$. falciparum isolates from children in Ghana. In contrast with a study by Amoah et al. in Ghana, who reported pfhrp 2 gene deletion in 33 and 36\% of microscopically confirmed and PCR-confirmed RDT-positive samples, respectively [21], all the isolates from this study achieved successful sequencing of the $p f h r p 2$ gene, 
Table 3 List of rare and novel pfhrp2 amino acid repeat types identified in Ghana

\begin{tabular}{|c|c|c|c|c|}
\hline Code & Known repeats & Rare/novel repeats & Repeat frequency & $\begin{array}{l}\text { Repeat } \\
\text { percentage }\end{array}$ \\
\hline \multirow[t]{3}{*}{ Type 1 motif } & AHHAHHVAD & AHHAHHVAY & 3 & 6.0 \\
\hline & & AHHTHHVAD & 1 & 2.0 \\
\hline & & APDAHHVAD ${ }^{\mathrm{a}}$ & 1 & 2.0 \\
\hline \multirow[t]{3}{*}{ Type 2 motif } & AHHAHHAAD & AHHAHHAPD & 1 & 2.0 \\
\hline & & AHHAHHADD & 2 & 4.0 \\
\hline & & AHHAHHAAH ${ }^{b}$ & 5 & 10.0 \\
\hline Type 5 motif & AHHAHHASD & AHHAPHASD & 1 & 2.0 \\
\hline \multirow[t]{2}{*}{ Type 7 motif } & AHHAAD & $\mathrm{AHHAA} \mathbf{H}^{\mathrm{b}}$ & 6 & 12.0 \\
\hline & & AHHADD & 1 & 2.0 \\
\hline Type 10 motif & AHHAAAHHATD & AHHAATHHATD & 1 & 2.0 \\
\hline \multirow[t]{2}{*}{ Type 12 motif } & AHHAAAHHEAATH & AHHAAAHHEAASH & 3 & 6.0 \\
\hline & & AHHAAAHDEAALI $^{\mathrm{a}}$ & 1 & 2.0 \\
\hline
\end{tabular}

Boldened amino acid shows the position where the rare/novel repeat types vary compared to known repeat types

a Previously unidentified repeat

${ }^{\mathrm{b}}$ More than one repeat copies per isolate

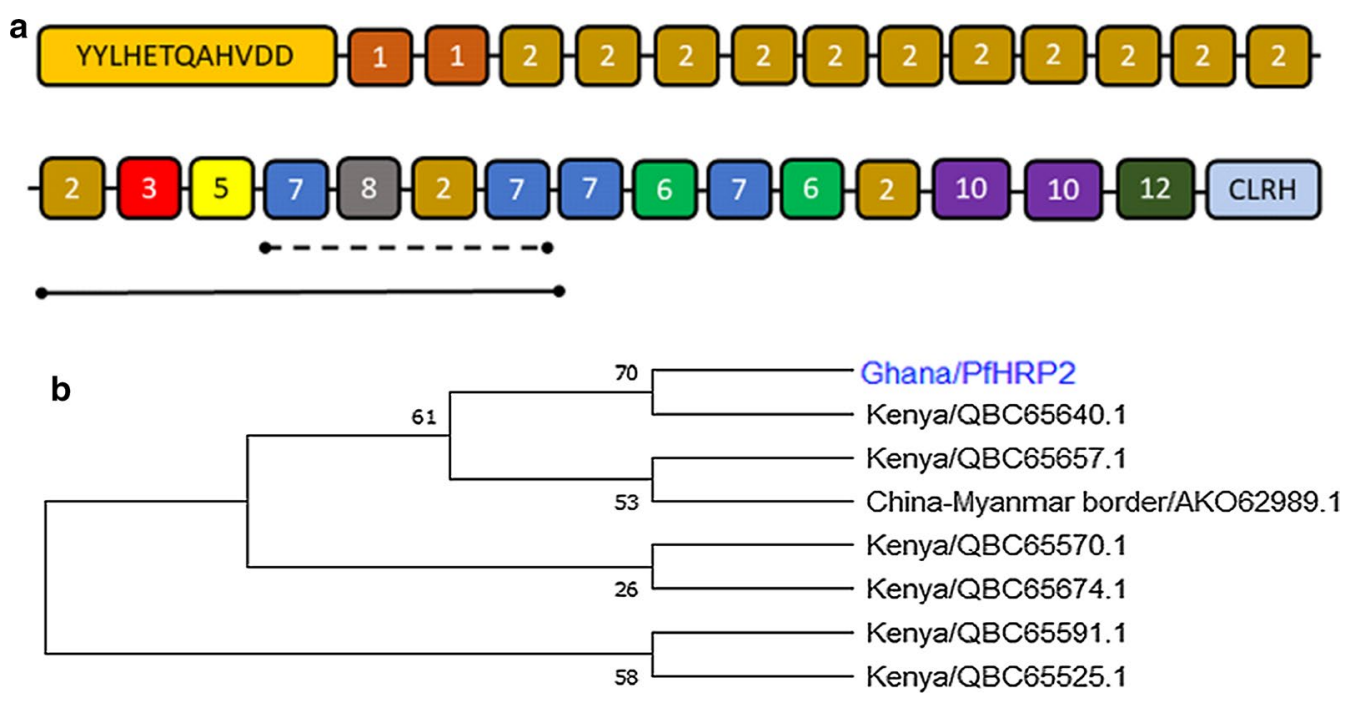

Fig. 2 Structural organization and relatedness between the Ghanaian pfhrp2 sequences and homologous sequences from other regions. a Schematic diagram of the structural organization of pfhrp2 amino acid repeat types in Ghana. The solid line represents semi-conserved amino acid repeat motif. The short dashes represent partial amino acid repeat motif. b Cladogram showing the relatedness between the Ghanaian pfhrp2 sequences and homologous sequences from other regions

Table 4 Frequency of occurrence of pfhrp2 groups (Baker model) in Ghana

\begin{tabular}{lcc}
\hline Diversity & Frequency & Percentages \\
\hline A & 2 & 4.0 \\
B & 29 & 58.0 \\
C & 11 & 22.0 \\
I & 8 & 16.0 \\
\hline
\end{tabular}

indicating absence of deletion. This finding is in harmony with studies by Baker et al. [16, 20] and Nderu et al. [18]. Compared with the study by Amoah et al., which was conducted in coastal parts of Ghana, the lack of pfhrp2 gene deletion in this study (conducted in the middle belt) suggests that geographical differences could play a role in $p f h r p 2$ gene diversity. Studies in other regions of the country are thus warranted. It should be noted, however, 
Table 5 Distribution of potential epitopes targeted by monoclonal antibodies in rapid diagnostic tests among Ghanaian isolates

\begin{tabular}{lllc}
\hline Monoclonal antibody & Epitope motif & Samples containing motif [n (\%)] & Motif per isolate \\
\hline C1-13 & AHHAADAHH & $50(100)$ & $12-21$ \\
3 A4 & AHHAHHA & $50(100.0)$ & $11-18$ \\
N7 & DAHHAADAHHA & $50(100)$ & $3-8$ \\
2G12-1C12 & DAHHAADAHH & $50(100)$ & $2-8$ \\
A6-4 & HATDAHH & $50(100)$ & $3-6$ \\
PTL-3 & YAHHAHHA & $50(100)$ & $1-4$ \\
S2-5 & AHHASDAHHA & $48(96.0)$ & $0-3$ \\
1E1-A9 & AHHAHHV & $47(94.0)$ & $0-9$ \\
TC-10 & TDAHHAADAHHAADA & $42(84.0)$ & $0-2$ \\
C2-3 & HAHHAHHAADAHH & $16(32.0)$ & $0-2$ \\
Genway & AYAHHAHHAAY & $0(0.0)$ & 0 \\
\hline
\end{tabular}

that inclusion of only symptomatic malaria cases and the limited sample size may have influenced the findings of this study. A larger sample size is recommended in future studies.

After in silico translation of the pfhrp 2 genes into amino acid sequences, the isolates from this study shared some characteristics with previous published data. Amino acid repeat types 2, 6, 7 and 8 were found in all isolates whereas types 9 and 11 were absent. Few of the isolates had the type 4 repeat and only $10 \%$ had the type 13 . All other repeat types were found in over $90 \%$ of the isolates. These findings are consistent with previous reports from other countries [18, 20, 31, 33-35].

The structural organization of the amino acid repeat types found in this study was highly diverse. Out of the 33 unqiue PfHRP2 sequences obtained, only a third occurred more than once. However, some repeat organizations were shared between isolates. Most of the sequences started with type 1 and all terminated with type 12 as is consistent with previous studies [18-20, 31]. Additionally, a semi-conserved PfHRP2 repeat type motif (types 2, 3, 5, 7, 8, 2, 7) and partial repeat motif (types $7,8,2,7$ ) were found in about half and a quarter of the isolates, respectively. This is similar to the findings of Baker et al. [20] and Nderu et al. [18]. Phylogenetic analysis of the Ghana PfHRP2 revealed striking similarities with isolates from Kenya. In a study along the Chinese-Myanmar border, novel PfHRP2 repeat types arising from replacement of a single amino acid of eight amino acid repeats types were identified [36]. Nderu et al. [18] also found 39 novel PfHRP2 repeat types. In India, Bharti et al. reported five novel repeat types [19]. In this study, two novel PfHRP2 repeat types (APDAHHVAD and AHHAAAHDEAALI) were identified in addition to 10 of the recently reported novel repeats which occurred at low frequencies. Together with previous reports, the findings of this study support the presence of yet-to-be defined repeat types and highlights that these novel types occur at relatively lower frequencies.

PfHRP2 diversity has been reported to influence the diagnosis of malaria using PfHRP2-based RDTs. In 2005, Baker et al. demonstrated, using logistic regression model, that the product of repeat types 2 and 7 affect inter-study sensitivity variation of PfHRP2-based RDTs, especially for samples with parasite densities $\leq 250$ parasites/ $\mu \mathrm{l}$ [16]. In 2010 however, it was found, using isolates from different geographical areas, that type $2 \times$ type 7 was not associated with RDT sensitivity [20]. Nonetheless, subsequent studies by Kumar et al. [33] in 2012 and Wurtz et al. [37] in 2013 observed an association between the Group $C$ category (type $2 \times 7<43$ ) and RDT false negativity and reduced limit of detection. Most of the isolates in this study were Group B (type $2 \times 7=50-100$ ) as consistent with previous studies in Africa [18, 38, 39]. To investigate the distribution of possible epitopes to be targeted by monoclonal antibodies in RDTs, a search for the 11 common epitopes recognized by commercially available mAb [32] among the isolates was performed. The most occurring epitope was AHHAADAHH, recognized by the $\mathrm{C} 1-13 \mathrm{mAb}$, followed by AHHAHHA, recognized by mAb 3A4. The AYAHHAHHAAY motif was not detected in this study and HAHHAHHAADAHH occurred at a lower frequency. This is consistent with recent reports by Fontecha et al. [31] and Willie et al. [40] and corroborates with an earlier report by Lee et al. that RDTs which employ the C2-3 and Genway mAbs are less sensitive [32].

It is worthy of note that, although deletion/diversity of $p f h r p 2$ gene could potentially impact RDT sensitivity, the product of the pfhrp3 gene can compensate for its absence in relation to the sensitivity of the tests. Moreover, RDTs recommended by WHO are capable of 
detecting the PfHRP2/PfHRP3 antigens together with parasite-specific lactate dehydrogenase (pLDH) or Plasmodium aldolase [11]. Thus, the absence of the PfHRP2 antigen (due to gene deletion/diversity) does not invalidate the available RDTs that are based on the other markers of infection. Furthermore, a major limitation of the study, which is worth considering by future studies in the region, is the unavailability of data on RDT.

\section{Conclusion}

This study reports diversity of $P$. falciparum histidinerich proteins 2 in samples from Ghanaian children with symptomatic malaria. Additionally, the findings of this study highlight the existence of extra amino acid repeat types which adds to the PfHRP2 antigenic variability. The findings of this study will contribute to the understanding of the performance of PfHRP2-based RDTs in the Ghanaian setting.

\section{Supplementary information}

Supplementary information accompanies this paper at https://doi. org/10.1186/s12936-020-03328-z.

Additional file 1. Primers used, BLASTP hits for HRP2 sequence modelled from Ghanaian isolates and BLASTP of Ghanaian HRP2 sequences for all 50 samples.

\section{Abbreviations}

PfHRP2: Plasmodium falciparum histidine-rich proteins 2; WHO: World Health Organization; RDT: Rapid diagnostic test; PCR: Polymerase chain reaction; BLAST: Basic Local Alignment Search Tool; mAb: Monoclonal antibodies.

\section{Acknowledgements}

The authors are grateful to the Staff of the Adidome Government Hospital and all who actively participated in the study.

\section{Authors' contributions}

OAM conceived the idea for the study. OAM and AYD supervised the research. OAM, BD, MN, SLA, MEAA, EWO, KM, RT, ET, CAK, CG, CAG and AYD contributed with the design of the study, collection of data and laboratory analysis. EWO analyzed, interpreted the data and wrote the manuscript. EWO, OAM and MEAA revised the manuscript. All authors read and approved the final manuscript.

\section{Funding}

This research did not receive any specific grant from funding agencies in the public, commercial, or not-for-profit sectors.

\section{Availability of data and materials}

The datasets supporting the conclusions of this article are included within the article and its additional file.

\section{Ethics approval and consent to participate}

The study was approved by the Committee on Human Research, Publications and Ethics (CHRPE/AP/606/19) of the School of Medical Sciences at Kwame Nkrumah University of Science and Technology. Written consent was obtained from parents and guardians of the children after the objectives of the study had been explained to them.

\section{Consent for publication}

Not applicable.

\section{Competing interests}

The authors declare that they have no competing interests.

\section{Author details}

${ }^{1}$ Department of Medical Diagnostics, Faculty of Allied Health Sciences,

Kwame Nkrumah University of Science and Technology, Kumasi 00233, Ghana. ${ }^{2}$ School of Basic and Biomedical Sciences, University of Health and Allied Sciences, Ho, Ghana. ${ }^{3}$ Laboratory Department, Ho Municipal Hospital, Ho, Ghana. ${ }^{4}$ Department of Molecular Medicine, School of Medicine and Dentistry, Kwame Nkrumah University of Science and Technology, Kumasi, Ghana.

Received: 25 February 2020 Accepted: 7 July 2020

Published online: 16 July 2020

\section{References}

1. WHO. World malaria report 2018. Geneva: World Health Organization; 2018. Available from: https://www.who.int/malaria/publications/world -malaria-report-2018/en/

2. WHO. World Malaria Report 2019. Geneva: World Health Organization; 2019. Available from: https://www.who.int/news-room/feature-stories/ detail/world-malaria-report-2019.

3. Addai-Mensah O, Annani-Akollor ME, Fondjo LA, Anto EO, Gyamfi D, Sallah $\mathrm{L}$, et al. High-sensitivity c-reactive protein: a potential ancillary biomarker for malaria diagnosis and morbidity. Dis Markers. 2019;2019:1408031.

4. Owusu-Agyei S, Asante K, Adjuik M, Adjei G, Awini E, Adams M. Epidemiology of malaria in the forest-savanna transitional zone of Ghana. Malar J. 2009;8:220.

5. Sarpong N, Owusu-Dabo E, Kreuels B, Fobil J, Segbaya S, Amoyaw F, et al. Prevalence of malaria parasitaemia in school children from two districts of Ghana earmarked for indoor residual spraying: a cross-sectional study. Malar J. 2015;14:260.

6. Addai-Mensah O, Annani-Akollor M, Fondjo L, Sarbeng K, Anto E, Owiredu $E$, et al. Regular antenatal attendance and education influence the uptake of intermittent preventive treatment of malaria in pregnancy: a cross-sectional study at the University Hospital, Kumasi, Ghana. J Trop Med. 2018;2018:5019215.

7. President's Malaria Initiative. Malaria Operational Plan Report Ghana. 2018.

8. Wongsrichanalai C, Barcus MJ, Muth S, Sutamihardja A, Wernsdorfer WH. A review of malaria diagnostic tools: microscopy and rapid diagnostic test (RDT). Am J Trop Med Hyg. 2007;77:119-27.

9. Incardona S, Serra-Casas E, Champouillon N, Nsanzabana C, Cunningham J, González IJ. Global survey of malaria rapid diagnostic test (RDT) sales, procurement and lot verification practices: assessing the use of the WHO-FIND Malaria RDT Evaluation Programme (2011-2014). Malar J. 2017;16:196.

10. Cunningham J, Jones S, Gatton ML, Barnwell JW, Cheng Q, Chiodini PL, et al. A review of the WHO malaria rapid diagnostic test product testing programme (2008-2018): performance, procurement and policy. Malar J. 2019;18:387.

11. Ugah UI, Alo MN, Owolabi JO, Okata-Nwali OD, Ekejindu IM, Ibeh N, et al. Evaluation of the utility value of three diagnostic methods in the detection of malaria parasites in endemic area. Malar J. 2017;16:189.

12. Moody A. Rapid diagnostic tests for malaria parasites. Clin Microbiol Rev. 2002;15:66-78.

13. Panton $L$, McPhie P, Maloy WL, Wellems TE, Taylor DW, Howard RJ. Purification and partial characterization of an unusual protein of Plasmodium falciparum: histidine-rich protein II. Mol Biochem Parasitol. 1989;35:149-60.

14. Boadu NY, Amuasi J, Ansong D, Einsiedel E, Menon D, Yanow SK. Challenges with implementing malaria rapid diagnostic tests at primary care facilities in a Ghanaian district: a qualitative study. Malar J. 2016;15:126.

15. Gamboa D, Ho M-F, Bendezu J, Torres K, Chiodini PL, Barnwell JW, et al. A large proportion of $P$. falciparum isolates in the Amazon region of Peru lack pfhrp2 and pfhrp3: implications for malaria rapid diagnostic tests. PLoS One. 2010;5:e8091.

16. Baker J, McCarthy J, Gatton M, Kyle DE, Belizario V, Luchavez J, et al. Genetic diversity of Plasmodium falciparum histidine-rich protein 2 
(PfHRP2) and its effect on the performance of PfHRP2-based rapid diagnostic tests. J Infect Dis. 2005;192:870-7.

17. Beshir KB, Sepúlveda N, Bharmal J, Robinson A, Mwanguzi J, Busula $\mathrm{AO}$, et al. Plasmodium falciparum parasites with histidine-rich protein 2 (pfhrp2) and pfhrp3 gene deletions in two endemic regions of Kenya. Sci Rep. 2017;7:14718.

18. Nderu D, Kimani F, Thiong'o K, Karanja E, Akinyi M, Too E, et al. Plasmodium falciparum histidine-rich protein (PfHRP2 and 3) diversity in Western and Coastal Kenya. Sci Rep. 2019:9:1709.

19. Bharti PK, Chandel HS, Krishna S, Nema S, Ahmad A, Udhayakumar V, et al. Sequence variation in Plasmodium falciparum histidine rich proteins 2 and 3 in Indian isolates: implications for malaria rapid diagnostic test performance. Sci Rep. 2017;7:1308.

20. Baker J, Ho M-F, Pelecanos A, Gatton M, Chen N, Abdullah S, et al. Global sequence variation in the histidine-rich proteins 2 and 3 of Plasmodium falciparum: implications for the performance of malaria rapid diagnostic tests. Malar J. 2010;9:129.

21. Amoah LE, Abankwa J, Oppong A. Plasmodium falciparum histidine rich protein-2 diversity and the implications for PfHRP 2: based malaria rapid diagnostic tests in Ghana. Malar J. 2016;15:101.

22. Parr JB, Verity R, Doctor SM, Janko M, Carey-Ewend K, Turman BJ, et al. Pfhrp2-deleted Plasmodium falciparum parasites in the Democratic Republic of the Congo: a national cross-sectional survey. J Infect Dis. 2017;216:36-44.

23. Menegon M, L'Episcopia M, Nurahmed AM, Talha AA, Nour BY, Severini C. Identification of Plasmodium falciparum isolates lacking histidine-rich protein 2 and 3 in Eritrea. Infect Genet Evol. 2017:55:131-4.

24. Berzosa P, González V, Taravillo L, Mayor A, Romay-Barja M, García L, et al. First evidence of the deletion in the pfhrp2 and pfhrp3 genes in Plasmodium falciparum from Equatorial Guinea. Malar J. 2020;19:99.

25. Gupta H, Matambisso G, Galatas B, Cisteró P, Nhamussua L, Simone W, et al. Molecular surveillance of pfhrp2 and pfhrp3 deletions in Plasmodium falciparum isolates from Mozambique. Malar J. 2017;16:416.

26. Kozycki CT, Umulisa N, Rulisa S, Mwikarago El, Musabyimana JP, Habimana JP, et al. False-negative malaria rapid diagnostic tests in Rwanda: impact of Plasmodium falciparum isolates lacking hrp2 and declining malaria transmission. Malar J. 2017;16:123.

27. Verner O, Kokou AA, Jones O-A, James O-Y, Ibrahim J, Innocent A, et al. Asymptomatic Plasmodium falciparum infection and poor school performance in primary school children in the Volta Region of Ghana. Ethiop J Health Sci. 2018;28:749-58.

28. WHO. Basic malaria microscopy - Part I: Learner's guide. $2^{\text {nd }}$ Edn World Health Organization; 2010. Available from: https://apps.who.int/iris/bitst ream/handle/10665/44208/9789241547826_eng.pdf;jsessionid=F5D7D 3AA5371D0B562103A5649F372C5? sequence $=1$.

29. Bereczky S, Martensson A, Gil JP, Färnert A. Rapid DNA extraction from archive blood spots on filter paper for genotyping of Plasmodium falciparum. Am J Trop Med Hyg. 2005;72:249-51.
30. Kumar S, Stecher G, Li M, Knyaz C, Tamura K. MEGA X: molecular evolutionary genetics analysis across computing platforms. Mol Biol Evol. 2018:35:1547-9.

31. Fontecha G, Pinto A, Escobar D, Matamoros G, Ortiz B. Genetic variability of Plasmodium falciparum histidine-rich proteins 2 and 3 in Central America. Malar J. 2019;18:31.

32. Lee N, Gatton ML, Pelecanos A, Bubb M, Gonzalez I, Bell D, et al. Identification of optimal epitopes for Plasmodium falciparum rapid diagnostic tests that target histidine-rich proteins 2 and 3. J Clin Microbiol. 2012;50:1397-405.

33. Kumar N, Singh JP, Pande V, Mishra N, Srivastava B, Kapoor R, et al. Genetic variation in histidine rich proteins among Indian Plasmodium falciparum population: possible cause of variable sensitivity of malaria rapid diagnostic tests. Malar J. 2012;11:298.

34. Atroosh WM, Al-Mekhlafi HM, Al-Jasari A, Sady H, Al-Delaimy AK, Nasr NA, et al. Genetic variation of pfhrp2 in Plasmodium falciparum isolates from Yemen and the performance of HRP2-based malaria rapid diagnostic test. Parasit Vectors. 2015;8:388.

35. Deme AB, Park DJ, Bei AK, Sarr O, Badiane AS, Gueye PEHO, et al. Analysis of pfhrp2 genetic diversity in Senegal and implications for use of rapid diagnostic tests. Malar J. 2014;13:34.

36. Li P, Xing H, Zhao Z, Yang Z, Cao Y, Li W, et al. Genetic diversity of Plasmodium falciparum histidine-rich protein 2 in the China-Myanmar border area. Acta Trop. 2015;152:26-31.

37. Wurtz N, Briolant S, Lemarie D, de Santi Pommier V, Pascual A, Roodt T, et al. Delayed diagnosis of Plasmodium falciparum in a soldier in Uganda: false-positive rapid diagnostic test associated with reduced repeats in pfhrp2. Med Sante Trop. 2013;23:181-4 (in French).

38. Wurtz N, Fall B, Bui K, Pascual A, Fall M, Camara C, et al. Pfhrp2 and pfhrp3 polymorphisms in Plasmodium falciparum isolates from Dakar, Senegal: impact on rapid malaria diagnostic tests. Malar J. 2013;12:34.

39. Mariette N, Barnadas C, Bouchier C, Tichit M, Ménard D. Country-wide assessment of the genetic polymorphism in Plasmodium falciparum and Plasmodium vivax antigens detected with rapid diagnostic tests for malaria. Malar J. 2008;7:219.

40. Willie N, Zimmerman PA, Mehlotra RK. Plasmodium falciparum histidinerich protein 2 gene variation in a malaria-endemic area of Papua New Guinea. Am J Trop Med Hyg. 2018;99:697-703.

\section{Publisher's Note}

Springer Nature remains neutral with regard to jurisdictional claims in published maps and institutional affiliations.

\footnotetext{
Ready to submit your research? Choose BMC and benefit from:

- fast, convenient online submission

- thorough peer review by experienced researchers in your field

- rapid publication on acceptance

- support for research data, including large and complex data types

- gold Open Access which fosters wider collaboration and increased citations

- maximum visibility for your research: over 100M website views per year
}

At $\mathrm{BMC}$, research is always in progress.

Learn more biomedcentral.com/submissions 